\title{
Comparison of serial synovial fluid cytology in rheumatoid arthritis: delineation of subgroups with prognostic implications
}

\author{
M J DAVIS, ${ }^{1}$ J DENTON, ${ }^{2}$ A J FREEMONT, ${ }^{2}$ AND P J L HOLT \\ From the ${ }^{\prime}$ Rheumatism Research Centre, Manchester Royal Infirmary, Oxford Road, Manchester; and the \\ ${ }^{2}$ Department of Rheumatology, University of Manchester Medical School, Oxford Road, Manchester
}

SUMMARY Serial synovial fluid samples were obtained from patients with rheumatoid arthritis and analysed cytologically. Positive correlations in the serial samples between proportions of polymorphs and ragocytes were found. Based upon the serial synovial fluid cytology, distinct subgroups of rheumatoid joints emerged. Comparison of clinical findings in these subgroups showed that the joints with high ragocyte proportion had a significantly poorer outcome. This study therefore identifies two distinct subgroups of rheumatoid joints on the basis of the nature of the cellular reaction within the joint fluid, which usually holds true during subsequent clinical relapse. Identification of these groups may have prognostic significance.

Key words: ragocytes, leucocytes.

Synovial fluid (SF) cytology when applied to a group of rheumatoid joints with active synovitis shows a heterogeneous picture in terms of total white cell count and in the proportions of polymorphs, mononuclear cells, and ragocytes ${ }^{1-3}$ (ragocytes being leucocytes with intracytoplasmic granules recognised in a wet smear of synovial fluid ${ }^{4}$ ). This variation is extreme with the total white cell range being $3-200 \times 10^{9} / 1,{ }^{6}$ and in the case of ragocytes from $3 \%$ to $97 \%$ of the leucocyte population. ${ }^{4}$ Polymorphonuclear cells predominate in most rheumatoid synovial effusions from inflamed joints.

There have been case reports suggesting that when SF is studied sequentially from joints over a period of time or from several joints in the same patient at one time that the SF cytological findings are more homogeneous in that joint or patient. ${ }^{78}$ The purpose of this study is to examine this observation further and to consider any difference between groups of rheumatoid joints that may emerge.

\section{Patients and methods}

PATIENTS

Criteria for patient entry to the study were as

Accepted for publication 13 January 1988.

Correspondence to Dr M J Davis, Staffordshire Rheumatology Centre, Haywood Hospital, High Lane, Burslem, Stoke-on-Trent ST6 7AG, Staffordshire. follows: (a) classical or definite rheumatoid arthritis $(\mathrm{RA})^{9} ;(b)$ serial SF from one or more joints had been analysed cytologically at any time during the period 1981-7; (c) all the joints were inflamed at the times of aspiration. Using these criteria we identified a group of 33 patients with relapsing rheumatoid joint disease, i.e., patients with RA who had had an inflamed joint aspirated then injected with local steroid with clinical improvement and then, at a later time, recurrent synovitis in the same joint necessitating reaspiration.

Clinical details obtained from the patients were age, sex, duration of disease, drug treatment at the time of the aspirations, and, finally, any local treatment administered to the joint during the course of the disease, such as joint injection, medical/surgical synovectomy, joint replacement, etc.

SYNOVIAL FLUIDS

All fluids aspirated were collected in $2 \mathrm{ml}$ paediatric dry lithium heparin bottles and processed the same day. Total white cell count was performed with a modified Fuchs-Rossenthal counting chamber. Cytocentrifuge preparations were made, ensuring a standard distribution and number of cells on each slide by diluting the SF with normal saline to give a concentration of $100 \mathrm{cells} / \mathrm{ml}$. A wet preparation was examined microscopically to ascertain the number 
of ragocytes as a percentage of the total leucocyte count. A Jenner-Giemsa stain was performed on a methanol fixed cytocentrifuged preparation to establish the proportions of polymorphs and mononuclear cells present.

STATISTICAL ANALYSIS

Correlation coefficients were calculated for the serial SF results. Fisher's exact probability test was used to analyse the subgroups of SF and their clinical outcomes.

\section{Results}

Seventy seven SF samples from 50 joints ( 47 knees, two elbows, one shoulder) were examined, 27 joints were aspirated twice. The interval between aspirations in these 27 joints varied from one to 18 months (median nine months) with treatment regimens being unaltered for 20 of these joints. In all but two of the 27 joints the interval between aspiration was three or more months. A variety of treatment regimens had been used, but all patients had been taking their respective second line drug for at least three months before the first aspiration.

Synovial fluid cytology at the two times was compared in these 27 joints. Positive correlations between proportions, though not absolute numbers, of polymorphs and ragocytes were found at the times of the two aspirations (correlation coefficient $r=0.68$ and 0.73 respectively, Fig. 1a). Correlation

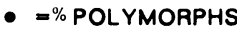

- $=\%$ RAGOCYTES

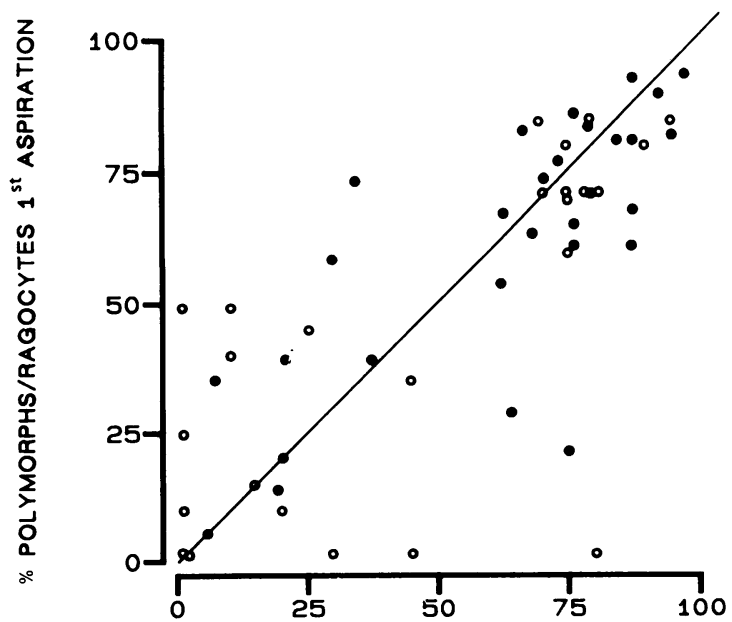

$\%$ POLYMORPHS/RAGOCYTES $2^{\text {Id }}$ ASPIRATION

Fig. 1a

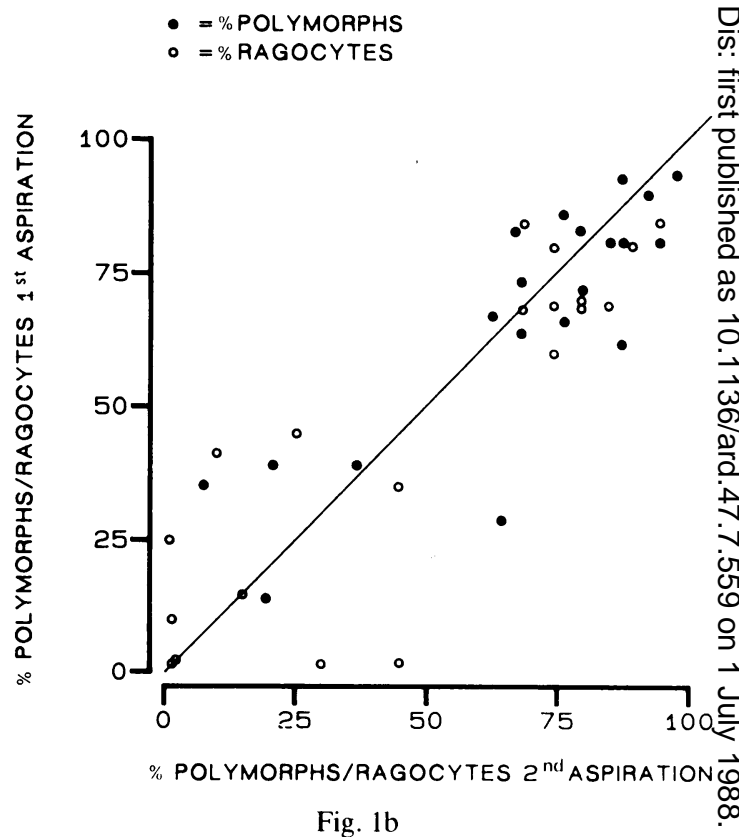

Fig. 1b

- = POLYMORPHS

$\bullet=$ RAGOCYTES

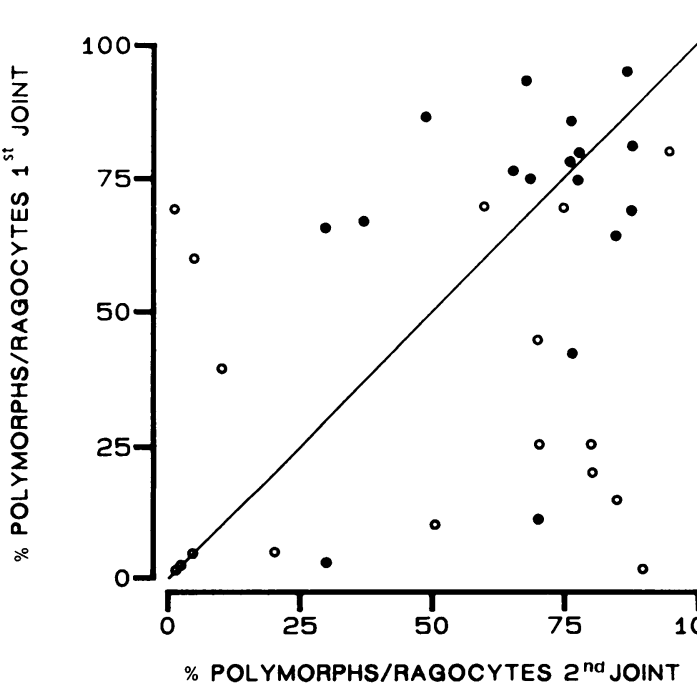

Fig. 1c

Fig. 1 Correlation between the percentage of polymorphs $(O)$ and of ragocytes $(O)$ in $(a)$ synovial fluid of 27 serially aspirated rheumatoid joints; (b) synovial fluid of 20

rheumatoid joints exposed to identical treatment between aspirations; (c) synovial fluid of non-identical joints in 17 patients with $R A$. 
was more significant when only joints in which the treatment was unchanged between aspirations were included $(r=0.82$ and $0 \cdot 87$, Fig. 1b). No correlation was found between total white cell count and the proportion of polymorphs and ragocytes, excluding this as a source of bias. The correlation remained significant for both polymorphs and ragocytes if the two joints whose time interval between reaspiration was less than three months were excluded from the analysis.

Comparison of SF cytology in 17 patients who had separate inflamed joints aspirated at different times during the study showed no correlation between the various cell types $(r=0.37$ for polymorphs and 0.19 for ragocytes, Fig. 1c). In addition, four patients had both knees aspirated on two occasions during the study. The results were similar in the SF cytology in each knee over time, but there was no similarity between the knees.

This suggests that our findings are 'joint specific' rather than 'patient specific'. Table 1 shows the findings in the group as a whole, indicating the heterogeneity found in rheumatoid joints.

When the SF findings from the 27 joints serially aspirated were considered two groups emerged: a

Table 1 Results of SF cytology in all RA joints studied (77 fluids)

\begin{tabular}{lcc}
\hline & Mean value & Range \\
\hline Total leucocyte count $/ 1$ & $14 \times 10^{9}$ & $1 \cdot 6-100 \times 10^{9}$ \\
\% Polymorphs & 65 & $7-98$ \\
\% Lymphocytes & 23 & $2-81$ \\
$\%$ Monocytes & 12 & $1-36$ \\
$\%$ Ragocytes & 41 & $1-98$ \\
\hline
\end{tabular}

All percentages are expressed as percentage of total leucocyte count.

Table 2 Clinical details in high/low ragocyte subgroups

\begin{tabular}{|c|c|c|}
\hline & High ragocytes* & Low ragocytest \\
\hline Number of joints & 11 & 15 \\
\hline Age (years) & $53 \cdot 5(18-74)$ & $52 \cdot 7(29-74)$ \\
\hline $\operatorname{Sex}(\mathbf{M}: \mathbf{F})$ & $4: 7$ & $6: 9$ \\
\hline $\begin{array}{l}\text { Disease duration to } 1 \text { st } \\
\text { aspiration (years) }\end{array}$ & $6 \cdot 2(0 \cdot 5-15)$ & $10 \cdot 1(1-25)$ \\
\hline $\begin{array}{l}\text { Disease duration to time of } \\
\text { evaluation of outcome } \\
\text { (years) }\end{array}$ & $8 \cdot 3(1-17)$ & $11.8(3-27)$ \\
\hline $\begin{array}{l}\text { Number of joints undergoing } \\
\text { synovectomy/joint } \\
\text { replacement }\end{array}$ & $6 \ddagger(54 \%)$ & $2 \ddagger(13 \%)$ \\
\hline
\end{tabular}

${ }^{*}$ High ragocytes $=>50 \%$ ragocytes as a proportion of total leucocytes on both aspirations.

†Low ragocytes $=\leqslant 50 \%$ ragocytes as a proportion of total leucocytes on both aspirations.

$\neq \mathrm{p}<0.05$ (Fisher's exact probability test). distinct population with high ragocyte proportions (11 joints) and a second population with low ragocyte proportions ( 15 joints). Table 2 shows the clinical details for these two groups. One joint had low ragocytes on first aspiration and high ragocytes on second aspiration and was therefore in neither group, and excluded for analysis. Comparison of clinical outcome in these subgroups showed that the joints with a high ragocyte proportion had a significantly poorer outlook when the end point of joint replacement or synovectomy was considered, despite a shorter mean length of disease. Thus a high proportion of ragocytes was associated with a more rapidly progressive disease in the aspirated joint if treatment did not reverse the ragocyte proportion.

\section{Discussion}

The heterogeneity of rheumatoid synovial fluids is confirmed in this study, our results being similar to others published..$^{1-3}$ In any one inflamed joint there is remarkable similarity in the SF cellular response when the joint relapses in the course of the disease, no matter what the treatment, but especially if treatment remains unaltered. This is only true for proportions of cell types not their absolute numbers. Previous case reports have suggested similar cell populations during the course of the disease in rheumatoid effusions, but we have studied this formally for the first time. ${ }^{78}$ The reasons for the stability of these results are not clear, but this stability suggests that the pathogenic mechanisms sustaining the inflammatory response in the joint remain constant although the intensity of the response varies.

Subgroups of RA joints emerge when serial SF cytology is performed. There are joints that sustain a predominance of ragocytes in their SF and others with a paucity of ragocytes. Conversely, independent of their ragocyte proportion, there are joints which have either a polymorph or lymphocyte predominance. In our study the lymphocyte predominant joints ( $>50 \%$ lymphocytes as a proportion of total leucocytes on both aspirations) are few (four of 27) and therefore have not been compared with the polymorph predominant joints in terms of clinical outcome.

The poorer clinical outcome in the ragocyte predominant group ( $>50 \%$ ragocytes as a proportion of total leucocytes on both aspirations) may be related to the nature of the ragocyte and subsequent events within the joint. Ragocytes are described as being leucocytes with intracytoplasmic granules. ${ }^{45}$ Immunofluorescence and other techniques have shown that these intracytoplasmic 
granules are the result of leococytes taking up immune complexes from the fluid. ${ }^{10}$ Ragocytes may therefore represent the immune complex status of the synovial fluid. During the process of phagocytosis of immune complexes the leucocyte lysosomes discharge enzymes which may mediate the proliferative and destructive changes seen in the joint. " This sequence of events could explain the significantly poorer outcome of those RA joints with a high proportion of ragocytes seen in this study.

We conclude that by studying SF cytology from RA joints with relapsing disease, subgroups based upon these findings can be delineated. In addition, this subgrouping identifies joints which fare worse over a period of time. Our study by its very nature can comment only on prognosis in RA joints necessitating (because of clinical relapse) reaspiration. Whether the ragocyte is an indicator of prognosis at a single point in time needs further study, but, if this is found to be so, our results suggest that the possible prognosis for a joint can be obtained after disease duration of six months (Table 2). In addition, the joints in our study were reaspirated in a relatively short space of time. A longer term study is required to examine whether our findings hold true for joints with a longer interval between relapse.
We would like to thank Mrs D Ward for typing the manuscript? This work was funded by a grant from the Arthritis and. Rheumatism Council.

\section{References}

1 Ropes M W. Bauer W. Synovial fluid changes in joint disease Cambridge: Harvard University Press, 1953: 27-32.

2 Currey H L F, Vernon-Roberts B. Examination of synoviaâ fluid. Clin Rheum Dis 1976; 2: 156-64.

3 Revell P A. Examination of synovial fluid. Curr Top Pathos 1982; 71: $5-8$

4 Hollander J E, McCarty D J, Astorga G, Castio-Murillo E Studies on the pathogenesis of rheumatoid joint inflammation 1. The 'RA cell' and a working hypothesis. Ann Intern Me 1965; 62: 271-80.

5 Delbarre F, Kahan A, Amor B, Krassinine G. Le ragocytêt synovial. Presse Med 1964; 72: 2129-32.

6 Krey P R, Bailen D A. Synovial fluid leucocytosis. A study of extremes. Am J Med 1979; 67: 436-42.

7 Bertina J R, Hollingsworth J W, Cashmore A R. Granulocyte kinctics in rheumatoid effusions by a biochemical label. Trans Assoc Am Physicians 1963; 76: 63-71.

8 Pekin T J, Zvaifler N J. Haemolytic complement in synovia fluid. J Clin Invest 1964; 43: 1371-82.

9 Ropes M W. Diagnostic criteria for rheumatoid arthritis. 1958 revision. Ann Rheum Dis 1959; 18: 49-53.

10 Zvaifler N J. The immunopathology of joint inflammation in rheumatoid arthritis. Adv Immunol 1973; 16: 316.

11 Weissmann G. Lysosomal mechanisms of tissue injury is arthritis. N Engl J Med 1972; 286: 141-7. 